\title{
An economic evaluation of a proprioceptive balance board training programme for the prevention of ankle sprains in volleyball
}

\author{
E A L M Verhagen, M van Tulder, A J van der Beek, L M Bouter, W van Mechelen
}

Br J Sports Med 2005;39:111-115. doi: 10.1136/bjsm.2003.011031

See end of article for authors' affiliations

.....................

Correspondence to: Professor van Mechelen, VU University Medical Centre, Department of Social Medicine and EMGO Institute, Van der Boechorststraat 7 . NL-1081 BT Amsterdam, the Netherlands; w.vanmechelen@vumc.nl

Accepted

17 February 2004 veness of a proprioceptive balance board training programme for Objectives: To evaluate the cost effectiveness
the prevention of ankle sprains in volleyball.

Methods: A total of 116 volleyball teams participated in this study which was carried out during the 20012002 volleyball season. Teams were randomly allotted to an intervention group ( 66 teams, 628 players) or a control group ( 52 teams, 494 players). Intervention teams followed a prescribed balance board training programme as part of their warm up. Control teams followed their normal training routine. An ankle sprain was recorded if it occurred as a result of volleyball and caused the subject to stop volleyball activity. The injured player completed a cost diary for the duration of the ankle sprain. Analyses were performed according to the intention to treat principle. Mean direct, indirect, and total costs were calculated and were compared between the two groups.

Results: The total costs per player (including the intervention material) were significantly higher in the intervention group (€36.99 (93.87)) than in the control group (€18.94 (147.09)). The cost of preventing one ankle sprain was approximately $€ 444.03$. Sensitivity analysis showed that a proprioceptive balance board training programme aimed only at players with previous ankle sprains could be cost effective over a longer period of time.

Conclusions: Positive effects of the balance board programme could only be achieved at certain costs. However, if broadly implemented, costs associated with the balance board programme would probably be lower.
$\mathrm{P}$ articipation in sport and physical activity is accompanied by the risk of injury. With the current promotion of a physically active lifestyle, an increased number of sports injuries can be expected. ${ }^{1}$ Fortunately, most are not life threatening, and the health benefits of sport and physical activity are generally greater than the risks involved. ${ }^{2}$ However, sports injuries can cause pain and other physical inconvenience, which result in use of healthcare resources and absenteeism from work. Owing to their demand on our financial healthcare resources, sports injuries have been suggested to be the most under-recognised public health problem. ${ }^{3}$

To reduce short and long term social and economic consequences, there is a need for sports injury prevention. Being the most common sports related injury, ankle sprains should be a major focus of sports injury prevention. It has been estimated that about $25 \%$ of all injuries across all sports are ankle injuries. ${ }^{4-7}$ Of all sports, volleyball has a relatively high incidence of ankle sprains considering its non-contact nature. ${ }^{7}$ This and the negative consequences for future sports participation should prompt preventive measures.

There is surprisingly little evidence on the effectiveness of preventive measures against ankle sprains from (randomised) controlled trials. Moreover, to our knowledge, evidence on the cost effectiveness of these preventive measures does not exist. Therefore we performed an economic evaluation alongside a controlled trial to evaluate the cost effectiveness of a proprioceptive balance board training programme for the prevention of ankle sprains in volleyball. In this article, we report on the economic evaluation and present costs and cost effectiveness. The effects on the incidence of ankle injuries have been reported in detail elsewhere. ${ }^{8}$

\section{METHODS}

\section{Population and randomisation}

Coaches of all 288 (men's and women's) teams from the second and third Dutch volleyball divisions were invited to participate in this one season (36 week), prospective study. A total of 116 teams consisting of 1127 players agreed to participate. The divisions invited were spread over four different geographical regions, in which second and third division teams competed against each other in regional competitions. These four geographical regions were randomised to an intervention group (two regions; 66 teams: 29 men and 37 women) or a control group (two regions; 50 teams: 20 men and 30 women). After informed consent had been obtained, the coaches of all participating teams were informed verbally about the purpose and procedures of the study, and instructed on the allocated intervention.

\section{Intervention}

During the 36 week follow up period, all players from the intervention group followed a set proprioceptive balance board training programme. The programme was designed in collaboration with sports physicians from the Dutch Volleyball Association and the Dutch National Olympic Committee. The programme consisted of 14 basic exercises on and off the balance board, with variations on each exercise and a gradual increase in difficulty and intensity during the 36 week volleyball season. ${ }^{8}$ During each warm up, one exercise was carried out, lasting no more than five minutes.

At the start of the season, coaches of the intervention teams were educated in the use of the prescribed balance

Abbreviations: NNT, number needed to treat; RD, risk difference 
Table 1 Costs included in the economic evaluation

\begin{tabular}{|c|c|}
\hline & Cost $(€)$ \\
\hline Intervention costs (per player) & 26.77 \\
\hline \multicolumn{2}{|l|}{ Direct healthcare costs } \\
\hline General practitioner (per visit $\leqslant 20 \mathrm{~min})^{*}$ & 16.60 \\
\hline General practitioner (phone consultation)* & 8.17 \\
\hline Physical therapist (per visit $\leqslant 30 \mathrm{~min})^{*}$ & 18.15 \\
\hline Sports physician (per visit)* & 16.60 \\
\hline Medical specialist (per visit)* & 40.85 \\
\hline Alternative therapist (per visit)† & 27.20 \\
\hline Radiograph/cast (per unit) $\ddagger$ & 50.00 \\
\hline Emergency room (per visit)‡ & 50.00 \\
\hline Drugs & - \\
\hline \multicolumn{2}{|l|}{ Medical devices } \\
\hline Tape (per roll) & 3.00 \\
\hline Brace & 67.89 \\
\hline Crutches (rent per week) & 15.00 \\
\hline \multicolumn{2}{|l|}{ Indirect costs } \\
\hline Absenteeism from paid work (per day)§ & - \\
\hline Absenteeism from unpaid work (per hour)* & 7.94 \\
\hline \multicolumn{2}{|c|}{$\begin{array}{l}€ 1.00=£ 0.70, \$ 1.09 \text { ( } 8 \text { September } 2003 \text { ). } \\
{ }^{*} \text { Guideline price according to Dutch guidelines. } \\
\text { †Price according to professional association. } \\
\text { †Cost price according to hospital administration of VU Medical Center. } \\
\text { "Drug specific price according to tariff of the Royal Dutch Society of } \\
\text { Pharmacy. } \\
\text { \$lndirect costs for paid work was calculated for each injured player } \\
\text { separately based on mean income of the Dutch population according to } \\
\text { age and sex. }\end{array}$} \\
\hline
\end{tabular}

board training programme by a trained sports physician or sports physical therapist. Each intervention team was provided with five balance boards, an instruction booklet, and an instructional videotape. In the videotape, players of the Dutch national under 21 team served as a role model to enhance the credibility of the intervention. Halfway through the season, all intervention teams were visited by a sports physician or a sports physical therapist to check compliance with and proper use of the balance board training programme. Players of the control group followed their usual training routine and used no balance boards.

\section{Data collection}

The coaches recorded volleyball exposure on a standardised form. The total duration of each training session and match was recorded, as well as the level of participation of each player (full, three quarters, half, quarter, or no participation). If a player did not fully participate, the coach noted the reason: injury, illness, or absence for other reasons. Completed exposure forms were returned on a weekly basis. The coach was contacted to obtain missing data.

An ankle sprain was recorded if it occurred as a result of volleyball, and caused the subject to stop volleyball activity or caused the subject to not fully participate in the next planned

Table 2 Subject characteristics and clinical outcome

\begin{tabular}{|c|c|c|}
\hline & $\begin{array}{l}\text { Intervention } \\
(n=641)\end{array}$ & $\begin{array}{l}\text { Control } \\
(n=486)\end{array}$ \\
\hline \multicolumn{3}{|l|}{ Subject characteristics } \\
\hline Mean (SD) age (years) & $24.4(2.8)$ & $24.2(2.5)$ \\
\hline Male & $286(45 \%)$ & 198 (41\%) \\
\hline In paid work & $376(59 \%)$ & $269(55 \%)$ \\
\hline \multicolumn{3}{|l|}{ Clinical outcome } \\
\hline Subjects with ankle sprain & $29(5 \%)$ & $41(8 \%)$ \\
\hline \multicolumn{3}{|c|}{ Sports absenteeism due to ankle sprains: } \\
\hline $0-2$ weeks & $13(45 \%)$ & $12(29 \%)$ \\
\hline $2-6$ weeks & $10(34 \%)$ & $19(46 \%)$ \\
\hline$>6$ weeks & $3(10 \%)$ & $6(15 \%)$ \\
\hline Unknown & $3(10 \%)$ & $4(10 \%)$ \\
\hline
\end{tabular}

volleyball activity. In the case of an ankle sprain, the coach provided the injured player with an injury registration form, which had to be completed within one week of the onset of injury. The player returned the form to the coach, who subsequently forwarded it to the research centre. When the research centre received an injury registration form, a cost diary was sent to the coach, who then forwarded it to the injured player. Injured players completed cost diaries for the duration of the injury - that is, the duration of absence from volleyball activities according to the exposure form.

If an ankle injury was noted on the exposure form and no injury registration form had been received within two weeks of the injury being logged, or if a player was still noted to be absent from volleyball because of the injury and no cost diaries were returned, the coach was contacted and urged to ask the player to complete the injury registration form or cost diary respectively.

\section{Outcomes}

Clinical outcome was ankle sprain incidence and its 95\% confidence interval (95\% CI), calculated as incidence of ankle sprains per 1000 playing hours. Recorded exposure and injury data of players without complete follow up were used in the analyses until they dropped out of the study. Ankle sprain risk difference (RD) and its corresponding 95\% CI was calculated for the intervention group compared with the control group.

Costs were collected from a societal perspective. Table 1 provides an overview of the costs analysed. ${ }^{910}$ Besides the cost of the intervention, direct healthcare costs were included: costs of care by a general practitioner, physiotherapist, massage therapist, alternative therapist, and care by a sports physician or medical specialist (for example, orthopaedic surgeon, general surgeon); hospital care; use of drugs (for example, paracetamol/acetaminophen, ibuprofen) and medical devices (for example, crutches, tape, braces). The costs of drugs were estimated on the basis of prices recommended by the Royal Dutch Society of Pharmacy. ${ }^{11}$ Also included were indirect costs resulting from loss of production due to absenteeism from paid or unpaid work. Indirect costs for absenteeism from paid work were calculated using the friction cost approach of four months, ${ }^{9}$ based on the mean age and sex specific income of the Dutch population. ${ }^{12}$ Indirect costs for productivity loss of unpaid work, such as study and household work, were estimated at a shadow price of $€ 7.94$ per hour. ${ }^{9}$

\section{Analysis}

Analyses were performed according to the intention to treat principle. Mean direct, indirect, and total costs were calculated and compared between the two groups, both for the costs per player in the injured population and for the costs per player in the total population. Costs were not normally distributed. Only a few players had high costs, and most players did not have any costs at all. Therefore confidence intervals for the differences in mean costs were obtained by bias corrected and accelerated bootstrapping (2000 replications).

For the cost effectiveness ratio, number needed to treat (NNT) was calculated from the ankle sprain RD to enable estimation of the costs associated with the prevention of one ankle sprain. RD represented the difference in ankle sprain incidence per 1000 hours, and the mean individual exposure was 97.43 (47.25) hours during the 36 week follow up period. Therefore NNT had to be adjusted to represent this mean individual exposure. Costs per ankle sprain prevented were then calculated by multiplying the adjusted NNT by the mean difference in total costs per player in the total population. Because the absolute number of ankle sprains 
Table 3 Absolute numbers and accumulated costs $(€)$ per category of use of healthcare resources and absenteeism from work, and total costs $(€)$ per group. Data are based on information derived from completed cost diaries only

\begin{tabular}{|c|c|c|c|c|}
\hline \multirow[b]{2}{*}{ Type of use } & \multicolumn{2}{|c|}{ Intervention $(n=17)$} & \multicolumn{2}{|c|}{ Control $(n=22)$} \\
\hline & Amount & Cost & Amount & Cost \\
\hline \multicolumn{5}{|l|}{ Direct healthcare costs } \\
\hline General practice (No of visits) & 6 & 99.60 & 10 & 166.00 \\
\hline General practice (No of phone consultations) & 1 & 8.17 & 1 & 8.17 \\
\hline Physiotherapist (No of visits) & 38 & 689.70 & 23 & 416.45 \\
\hline Sports physician (No of visits) & 3 & 49.80 & 4 & 66.40 \\
\hline Medical specialist (No of visits) & 7 & 285.95 & 1 & 40.85 \\
\hline Alternative therapist (No of visits) & - & - & 2 & 54.40 \\
\hline Radiograph/cast & 3 & 150.00 & 5 & 250.00 \\
\hline Emergency room (No of visits) & 3 & 150.00 & 4 & 200.00 \\
\hline Drugs & & 36.94 & & 75.15 \\
\hline \multicolumn{5}{|l|}{ Medical devices } \\
\hline Tape (No of rolls) & 9 & 27.00 & 13 & 39.00 \\
\hline Brace & 5 & 339.45 & - & - \\
\hline Crutches (No of times rented) & 1 & 15.00 & 1 & 15.00 \\
\hline \multicolumn{5}{|l|}{ Indirect costs } \\
\hline Absenteeism from paid work (days) & 41 & 3447.61 & 51 & 2629.51 \\
\hline Absenteeism from unpaid work (hours) & 174 & 1381.56 & 655 & 5200.70 \\
\hline Total costs & & 6680.78 & & 9161.63 \\
\hline
\end{tabular}

was low and therefore most players had an effect equal to zero- that is, no ankle injury-95\% confidence intervals and cost effectiveness planes associated with these costs could not be calculated.

\section{RESULTS}

The participating 66 intervention teams and 50 control teams consisted of 641 and 486 players respectively (table 2). At baseline, no significant differences in any of the variables were found between the groups (data not shown). A total of 70 ankle sprains were recorded during the 36 week follow up. Complete cost diaries were returned by $22(54 \%)$ players in the control group and 17 (59\%) players in the intervention group.

The subjects who did not complete the cost diaries (noncompleters) did not differ significantly from those who did (completers) with regard to relevant variables (age, years of volleyball, duration of ankle injury, and previous ankle injury) except for sex (14 (34\%) female non-completers $v$ $17(55 \%)$ male non-completers). Therefore, in a secondary analysis, cost data for the 31 non-completers were imputed using the mean costs for men and women in the intervention and control groups.

\section{Effect of intervention}

The incidence of ankle sprain was 0.5 per 1000 playing hours (95\% CI 0.3 to 0.6 ) in the intervention group and 0.9 per 1000 playing hours (95\% CI 0.6 to 1.2 ) in the control group. With an RD of 0.4 per 1000 playing hours (95\% CI 0.1 to 0.7 ), the ankle injury incidence in the intervention group was significantly lower than in the control group. A subgroup analysis for players with a history of ankle sprains also showed a significant difference in incidence of ankle sprain in favour of the intervention group $(\mathrm{RD}=0.5 ; 95 \% \mathrm{CI} 0.1$ to $0.9)$. No difference was observed for players without a history of ankle sprain ( $\mathrm{RD}=0.2 ; 95 \% \mathrm{CI}-0.3$ to 0.7$)$.

\section{Healthcare use and absenteeism from work}

Table 3 shows the use and subsequent costs of healthcare resources and absenteeism from work for the 39 diary completers. In the intervention group, 14 of the 17 completers $(73 \%)$ reported having had costs due to their ankle injury; in the control group 17 of the 22 completers $(77 \%)$ reported costs.

In the intervention group, four (24\%) completers reported a total of seven visits to a medical specialist, whereas one $(5 \%)$ visit to a medical specialist was reported in the control

Table 4 Mean (SD) total costs $(€)$ and differences in mean total costs (95\% confidence intervals)

\begin{tabular}{|c|c|c|c|c|c|}
\hline & \multirow[b]{2}{*}{ Intervention } & \multirow[b]{2}{*}{ Control } & \multirow[b]{2}{*}{ Difference } & \multicolumn{2}{|l|}{$95 \% \mathrm{Cl}$} \\
\hline & & & & Lower & Upper \\
\hline \multicolumn{6}{|c|}{ Per player in the injured population $(n=39)$} \\
\hline Direct costs & $101.43(74.10)$ & $56.77(48.07)$ & 44.67 & 2.99 & 90.90 \\
\hline Indirect costs & $284.07(409.68)$ & $361.69(541.28)$ & -77.62 & -403.98 & 203.11 \\
\hline Total costs* & $412.27(445.82)$ & $418.46(569.70)$ & 6.20 & -323.51 & 313.51 \\
\hline \multicolumn{6}{|c|}{ Per player in the injured population ( $n=70$; imputed data) } \\
\hline Direct costs & $96.28(57.03)$ & $42.50(42.33)$ & 53.78 & 27.58 & 81.43 \\
\hline Indirect costs & $282.73(310.30)$ & $318.10(401.13)$ & -35.37 & -210.11 & 121.08 \\
\hline Total costs* & $405.78(338.28)$ & $360.60(426.73)$ & 45.19 & -198.42 & 207.87 \\
\hline \multicolumn{6}{|c|}{ Per player in the total population $(n=1127)$} \\
\hline Direct costs & $2.69(20.08)$ & $2.57(15.48)$ & 0.12 & -2.03 & 2.27 \\
\hline Indirect costs & $7.53(79.26)$ & $16.37(135.47)$ & -8.84 & -22.38 & 4.70 \\
\hline Total costs* & $36.99(93.87)$ & 18.94 (147.09) & 18.05 & 3.92 & 32.18 \\
\hline
\end{tabular}


group. For the other healthcare cost categories, the percentage of completers in each group who reported healthcare use did not differ, and observed differences in costs are due to differences between individual completers in quantity of healthcare use.

Although in both groups $35 \%$ of the completers visited a hospital, no admission because of the injury was reported. Absenteeism from paid work was reported by eight $(47 \%)$ and $10(45 \%)$ of the completers in the intervention group and control group respectively. Absenteeism from unpaid work was reported by nine $(53 \%)$ completers in the intervention group and by 10 (45\%) completers in the control group.

\section{Costs}

Each team used five balance boards (€50 a piece) and received a videotape and book worth $€ 10$. Consequently, the intervention costs per team were $€ 260$. The 66 teams in the intervention group included a total of 641 players making the total intervention costs per player €26.77.

Table 4 shows the mean (SD) costs for both the intervention group and the control group, and differences between groups with $95 \%$ CIs. For the intervention group the total costs per player in the injured population were $€ 412.27$ (445.82) without imputed data $(\mathrm{n}=17)$ and $€ 405.78$ (338.28) with imputed data $(\mathrm{n}=29)$. In the control group these costs were comparable: $€ 418.46$ (569.70) without imputed data $(\mathrm{n}=22)$ and $€ 360.60$ (426.73) with imputed data $(n=41)$. Direct costs per player in the injured population in the intervention group were significantly higher, both in the analysis with imputed data and in the analysis without imputed data. No significant differences were found for indirect costs.

The total cost per player, including the cost of the intervention material, for the total population was on average $€ 36.99$ (93.87) in the intervention group $(\mathrm{n}=641)$ and $€ 18.94$ (147.09) in the control group ( $\mathrm{n}=486)$. With a mean difference of $€ 18.05$ (95\% CI 3.92 to 32.18 ), the total mean costs per player in the total population were significantly higher in the intervention group than in the control group. No significant differences were found for direct and indirect costs,

Based on the overall RD of 0.4 ankle sprains per 1000 playing hours between the intervention group and the control group, the NNT in the total population was 2.4. Taking the mean individual exposure of 97.43 (47.25) hours into account, in the present 36 week study, the NNT was 24.6 in the total population. This implies that the cost of preventing one ankle sprain was approximately $€ 444.03$.

\section{Sensitivity analysis}

The cost difference between the groups was entirely due to the costs of the intervention material ( $€ 26.77$ per player). As pointed out above, the clinical results showed an effect only for players with previous ankle sprains. However, in our study the intervention was prescribed for all players, and all participating teams needed five balance boards. If the intervention programme had been prescribed for players with a previous ankle sprain only, a maximum of two balance boards per team would have sufficed. This would have lowered the actual costs of the intervention per player to $€ 11.33$ and the total costs per player in the intervention group to $€ 21.55$. Based on the $\mathrm{RD}$ of 0.5 ankle sprains per 1000 playing hours, the NNT in the previously injured population was 2.0. Taking the mean individual exposure of 101.25 (46.97) hours of this subpopulation into account, the NNT was 19.8. This implies that the cost of preventing one ankle sprain in a previously injured player would be about $€ 51.68$.
Furthermore, costs were calculated over the 36 week intervention period only, whereas the cost of a balance board could actually be written off over three seasons. If the intervention was aimed at players with previous ankle sprains, and the cost of the intervention material was spread over three years, costs would be further reduced to an estimated $€ 3.78$ per player per season. This implies that, in the long term, a proprioceptive balance board training programme for the prevention of acute lateral ankle ligament injuries is cost beneficial.

\section{DISCUSSION}

A proprioceptive balance board training programme for the prevention of acute lateral ankle ligament injuries proved effective for players with a history of ankle sprains. ${ }^{8}$ The total mean costs were slightly higher in the intervention group than in the control group. The cost of preventing one ankle sprain was approximately $€ 444.03$.

Although this study is to our knowledge the first to prospectively investigate the costs associated with a preventive measure for sports injuries, the results and conclusions should be handled with care. We encountered difficulties in recording the cost data. Because of the size of the study population (1127), it was decided that the coaches of the 116 teams would serve as intermediaries to the players. Although this resulted in near complete data for exposure and injuries, ${ }^{8}$ this method of recording data reduced our follow up control over the individual injured players. This led to the substantial amount of missing cost diary data. Only 39 of the 70 injured players recorded costs. Although we imputed data for the 31 non-completers, the large number $(44 \%)$ remains a critical point. We recommend that, in future trials, cost data are collected directly from the players.

Although a significantly lower incidence of ankle sprains was found in the intervention group, it should be noted that a higher incidence of knee injuries was observed in the intervention group. ${ }^{8}$ Although the increased risk of knee injury was relatively small $(\mathrm{RD}=-0.2$ per 1000 playing hours, 95\% CI -0.4 to -0.0 ) and all knee injuries were minor, additional costs due to this increase in knee injuries can be expected. Unfortunately, as the balance board training programme only targeted ankle sprains, and an increase in knee injury incidence was not expected beforehand, only costs related to ankle sprain were recorded during our study. Therefore, in the intervention group, the mean total costs associated with the proprioceptive balance board training programme were probably somewhat higher than the calculated $€ 444.03$.

Although it can be speculated that, in practice, the cost of preventing one ankle sprain would be lower, the question remains whether the costs associated with a proprioceptive balance board training programme are worth the effects. There seems to be a certain unpreventable baseline risk of ankle sprains and a high risk of recurrence. ${ }^{73-15}$ It has been found that $20-50 \%$ of these recurrences can result in disability and lead to chronic pain or instability ${ }^{16}$ and even arthritis later in life. ${ }^{17}$ Furthermore, considering the noncontact nature of volleyball compared with other sports, it has a relatively high incidence of ankle sprains. ${ }^{7}$ Based on this knowledge and the clinical results showing that a proprioceptive balance board training programme was effective for players with a history of ankle sprains, ${ }^{8}$ we recommend the introduction of such a training programme in volleyball in general.

\section{CONCLUSIONS}

Although the positive effects of the balance board programme were only achieved at certain cost, it is likely that the costs associated with such a programme would be 


\section{What is already known on this topic}

No previous attempts have been made to establish the economic consequences of a working prevention programme for sports injuries, in general, and ankle sprains, in particular. An attempt was made to estimate the costs associated with the use of tape or braces through post hoc cost analysis of previously published preventive studies. Although it was clearly shown that braces are cheaper to use than tape, there were no conclusions on the direct and indirect medical costs that could be averted through prevention of injuries.

\section{What this study adds}

This study shows that the introduction of a proprioceptive balance board training programme to prevent ankle sprains requires financial investment in the short term. However, long term effective preventive measures are likely to have economic benefits from a societal point of view.

considerably lower if the target population were defined more strictly and prolonged use of the intervention material were taken into account. A broader implementation of this preventive measure in volleyball can be recommended if the long term health burden of ankle sprains and the clinical effectiveness of a proprioceptive balance board training programme are considered.

\section{ACKNOWLEDGEMENTS}

This study was supported financially by the Netherlands Organisation for Health Research and Development (ZonMw; grant No 2200.0068) and the project group Sport Blessure Vrij (SBV) of the Dutch National Olympic Committee (NOC ${ }^{*} \mathrm{NSF}$ ). We also thank the Dutch Volleyball Association for their cooperation. Furthermore, we are grateful for the help given by M Inklaar in collecting the data.

\section{Authors' affiliations}

E A L M Verhagen, M van Tulder, A J van der Beek, L M Bouter, $W$ van Mechelen, EMGO Institute, VU University Medical Centre, Amsterdam, the Netherlands

Competing interests: none declared

\section{REFERENCES}

1 Parkkari J, Kujala UM, Kannus P. Is it possible to prevent sports injuries? Review of controlled clinical trials and recommendations for future work. Sports Med 2001;31:985-95.

2 Stam PJA, Hildebrandt VH, Backx FJG, et al. Sportief bewegen en gezondheidsaspecten: een verkennende studie naar kosten en baten (SEOrapport nr. 372). Amsterdam: Stichting voor Economisch Onderzoek der Universiteit van Amsterdam, 1996.

3 Janda DH. Sports injury surveillance has everything to do with sports medicine. Sports Med 1997;24:169-71.

4 Wexler FK. The injured ankle. Am Fam Physician 1988;57:474-80.

5 Bylak J, Hutchinson MR. Common sports injuries in young tennis players. Sports Med 1998;6:119-32.

6 Creagh U, Reilly T. Training and injuries amongst elite female orienteers. J Sports Med Phys Fitness 1998;38:75-9.

7 Bahr R, Bahr IA. Incidence of acute volleyball injuries: a prospective cohort study of injury mechanisms and risk factors. Scand J Med Sci Sports 1997;7:166-71.

8 Verhagen EALM, Van der Beek AJ, Twisk JWR, et al. The effect of a proprioceptive balance board training program for the prevention of ankle sprains a prospective controlled trial. Am J Sports Med 2004;32:1385-93.

9 Oostenbrink JB, Koopmanschap MA, Rutten FF. Handleiding voor kostenonderzoek, methoden en richtlijnprijzen voor economische evaluaties in de gezondheidszorg. The Hague, Netherlands: Health Care Insurance Council, 2000.

10 Dutch Central Organisation for Health Care Charges. Tarieven voor medisch specialist, exclusief psychiaters, Bijlage bij tariefbeschikking nummer 56001900-97. Utrecht: CTG, 1996.

11 Tax report. The Hague, The Netherlands: Z-index, 2000

12 Koopmanschap MA, Rutten FF. A practical guide for calculating indirect costs of disease. Pharmacoeconomics 1996;10:460-6.

13 Tropp H, Askling C, Gilquist J. Prevention of ankle sprains. Am J Sports Med 1985;13:259-61.

14 Ekstrand J, Tropp H. The incidence of ankle sprains in soccer. Foot Ankle $1990 ; 11: 41-4$

15 Milgrom C, Shlamkovitch N, Finestone A, et al. Risk factors for lateral ankle sprains: a prospective study among military recruits. Foot Ankle $1991 ; 12: 26-30$

16 Sander E. Ligamentous injuries to the ankle. Am Fam Physician 1980;22:132-8.

17 Kujula U, S Orava S, J Parkkari J, et al. Sports career-related musculoskeletal injuries: long-term health effects on former athletes. Sports Med 2003;33:869-75 